Original Research Paper

\title{
Inhibition of Panton-Valentine Leukocidin Toxin Induced Neutrophil Cell Lysis by Vancoplus in Methicillin-Resistant Staphylococcus aureus Infections
}

\author{
Manu Chaudhary, Santosh Kumar Patnaik and Anurag Payasi \\ Venus Medicine Research Centre, Hill Top Industrial Estate, Bhatoli Kalan, Baddi, H.P.-173205, India
}

\author{
Article history \\ Received: 2014-09-11 \\ Revised: 2014-11-01 \\ Accepted: 2014-01-05 \\ Corresponding Author: \\ Manu Chaudhary, \\ Venus Medicine Research \\ Centre, Hill Top Industrial \\ Estate, Bhatoli Kalan, Baddi, \\ H.P.-173205, India \\ E-mail: ccmb@vmrcindia.com
}

\begin{abstract}
Pantone Valentine Leukocidin (PVL) is a cytotoxin associated with virulence of Methicillin-Resistant Staphylococcus aureus (MRSA). This study was undertaken to analyze the prevalence of PVL among MRSA strains and to study the effect of adjuvants (L-lysine, L-arginine, Ethylenediamine Tetraacetic Acid (EDTA) as well as drugs on PVL induced neutrophil cell lysis. Further, in vitro activity of Vancoplus, vancomycin, linezolid, teicoplanin and daptomycin against PVL positive MRSA strains was analyzed. A total of 67 Staphylococcus aureus strains collected were screened for the prevalence of methicillin resistance and PVL by Polymerase Chain Reaction (PCR). Effects of various adjuvants and drugs on PVL induced neutrophil cell lysis were studied by Lactate Dehydrogenase (LDH) assay. Antibiotic susceptibility was conducted using Clinical and Laboratory Standards Institute (CLSI) guidelines. Our results showed that of 67 clinical isolates, $71.6 \%$ (48/67) isolates were confirmed to be MRSA. Of these MRSA strains, $75 \%(36 / 48)$ isolates were observed to be PVL positive. Pus swab $(86.3 \% ; 19 / 22)$ had more proportion of PVL than urine $(75 \% ; 6 / 8)$; sputum $(70 \% ; 7 / 10)$ and blood $(50 \% ; 4 / 4)$. When diverse adjuvants alone (L-lysine, Largine and EDTA) or in combinations were tested on PVL induced neutrophil cell lysis, $10 \mathrm{mM}$ L-lysine alone and combinations of $10 \mathrm{mM}$ L-lysine $+10 \mathrm{mM}$ EDTA and $100 \mathrm{mM}$ L-arginine $+10 \mathrm{mM}$ EDTA produced the highest $78.7 \pm 7.1$, $92.6 \pm 8.8$ and $93.4 \pm 6.3 \%$, respectively, inhibition of LDH activity (known marker of cell lysis). Further, when Vancoplus reconstituted with solvent produced $93.1 \pm 6.4 \%$ inhibition of $\mathrm{LDH}$ activity whereas other comparator drugs produced only $12.7 \pm 2.4$ to $30.5 \pm 3.1 \%$ inhibition of LDH activity. Vancoplus appeared to be the most efficacious against $94.4 \%$ of the MRSA strains with MIC values 0.25 to $4 \mu \mathrm{g} \mathrm{mL}^{-1}$. The susceptibility of other drugs vancomycin, linezolid, teicoplanin and daptomycin against MRSA varied from 22.3 to $77.8 \%$ of isolates with MICs 0.5 to $32 \mu \mathrm{g} \mathrm{mL}^{-1}$. This study provides new insight into the prevalence of PVL toxins among MRSA. Results of this study showed that Vancoplus is the most active against MRSA and it additionally protects the neutrophil cells from PVL toxins and prevents from sequels of MRSA infections caused by these cytotoxins.
\end{abstract}

Keywords: Adjuvants, Clinical Isolates, Methicillin-Resistant Staphylococcus aureus, Panton-Valentine Leukocidin

\section{Introduction}

Staphylococcus aureus is an opportunistic Grampositive pathogen that is frequently associated with various types of life-threatening hospital and community acquired infections (Nizet, 2007; Nubel et al., 2008). It commonly causes necrotic lesions in skin, necrotic hemorrhagic pneumonia as well as endocarditis (Holmes et al., 2005; Corey, 2009). Approximately
$80 \%$ of the human population has this bacteria in skin (Kluytmans et al., 1997).

The presence of antibiotic resistant genes as well as production of virulence factors makes $S$. aureus highly pathogenic organism. Methicillin-Resistant S. aureus (MRSA) is one of the most prevalent forms of antimicrobial-resistant bacteria (Baba-Moussa et al., 2010). The virulence factors which are produced by this organism includes exotoxins, such as Exfoliative Toxins 
(ETs), along with Toxic Shock Syndrome Toxin-1 (TSST-1), Staphylococcal Enterotoxins (SEs), leukocidins (Panton-Valentine Leukocidin; PVL, LukE/D) and hemolysins $(\alpha, \beta, \gamma, \delta)$. These toxins create a survival advantage for the bacteria by forming pores into the membrane of target cells, inducing cell death and weakening the host during infections (Dinges et al., 2000; Sina et al., 2013). Among these virulence factors, PVL is reported to be an important virulence factor for $S$. aureus (Clinic et al., 1992). It is made up of two components called LukS-PV and LukF-PV which work synergistically to damage the membranes of macrophages and polymorphonuclear leukocytes, important components of the immune response (Prevost et al., 1993).

According to a study, approximately $93 \%$ of the community-associated $S$. aureus causing skin infections such as furnucles, possessed the PVL genes (Lina et al., 1999). Another study reported that around $96 \%$ cases of furuncles are associated with PVL positive strains of $S$. aureus (Durupt at al., 2007). PVL has also been shown to be involved in necrotizing pneumonia (Labandeira-Rey et al., 2007) and osteomyelitis (Gillet et al., 2007).

It has been proposed that MRSA strains that have the ability to cause severe skin and soft tissue infections, do so in a PVL-dependent manner (Lina et al., 1999). Upon infection with PVL-expressing $S$. aureus, the recruited neutrophils are rapidly killed by PVL, resulting in uncontrolled release of neutrophil proteases that damage the airway epithelium and thus damage immune system causing necrotizing pneumonia (Niemann et al., 2012). It indicates that proteases released by PVL-damaged neutrophils are mainly responsible for lung injury and neutrophil killing during infection with PVL-producing strains. The host counteracts this pathogen strategy by using PVL-neutralizing beta-sheet breakers/terminal blocking groups or by neutralizing the released proteases via protease inhibitors (Korkmaz et al., 2008). Lysine and arginine are essential amino acids known to be protease inhibitors (Korkmaz et al., 2008). A variety of antibiotics including vancomycin have routinely been used for the treatment of $S$. aureus infections specially MRSA strains. However, persistence use of vancomycin caused development of Vancomycin-Resistant $S$. aureus (VRSA) and VancomycinIntermediate $S$. aureus (VISA). The resistant genes may also affect toxin production (Sina et al., 2013).

A study in last deacde showed a $76 \%$ treatment failure rate with vancomycin (Howden et al., 2004). Several reports from India recorded the emergence of various degree of vancomycin resistance (Veer et al., 2010; Thati et al., 2011). Other parts of the world also reported the prevalence of vancomycin resistance (Perichon and Courvalin, 2009; Reynolds et al., 2012; Jang et al., 2012). Similarly, the rate of non-susceptibility of penicillin-resistant Streptococcus pneumoniae to cephalosporins particularly ceftriaxone is increasing significantly (Karunakaran et al., 2012). In such scenerio, where cephalosporins and vancomycin are getting resistant individually, an unmet medical need to cater growing vancomycin resistance and to counter the toxins produced by MRSA is required.

This study was aimed to study the prevalence of PVL in MRSA and to study the effect of adjuvants (L-lysine, L-arginine, EDTA) and drugs on PVL induced neutrophil cell lysis. In addition, in vitro activity of different drugs used to treat MRSA infections was studied to check their susceptibility behaviour.

\section{Materials and Methods}

\section{Chemicals}

Primary monoclonal antibody (Mouse anti-Luks-PV mAB), secondary antibody (anti Horseradish Peroxidase (HRP) conjugate) and detection antibody (polyclonal anti PVL LukS) were obtained from Institute of Biosciences and Technology (IBT), USA. 3,3',5,5'-Tetramethylbenzidine (TMB) substrate was obtained from Cell Signaliing Technologies (CST), USA. Taq polymerase was purchased from Merck Milipore Genei (Banglore). Ficollpaque PLUS and Latacte Dehydrogenase (LDH) assay kit were obtained from Sigma Aldrich, USA. RPMI-1640 medium, Bovine Serum Albumin (BSA), sodium chloride $(\mathrm{NaCl})$, sodium Hydroxide $(\mathrm{NaOH})$, monosodium phosphate $\left(\mathrm{NaH}_{2} \mathrm{PO}_{4}\right)$, sodium phosphate dibasic $\left(\mathrm{Na}_{2} \mathrm{HPO}_{4}\right)$, agarose, ammonium sulfate, tween-20, proteinase K, Soyabean Casein Digest Medium (SCDM), lysine, arginine, Ethylenediamine Tetraacetic acid Disodium (EDTA) and mannitol salt agar were purchased from Hi-Media (Mumbai, India). HEPES buffer was purchased from Spectrochem Limited (Mumbai, India).

\section{Antibacterial Agents}

The following antibiotics were used in this study: A novel antibiotic adjuvant entity of ceftriaxone sodium and vancomycin hydrocloride with VRP1020 (Vancoplus; Venus Remedies Limited, Chandigarh, India), teicoplanin (T-planin, Glenmark, India), linezolid (Linospan injection, Cipla Limited, Mumbai, India), daptomycin (cubicin; Novartis Pharmaceuticals, United Kingdom) and vancomycin (vancocin-CP, Astra Zeneca Pharma India Limited, Banglore, India). All the drugs were reconstituted according to the instructions of the manufacturer.

\section{Bacterial Isolates Collection and their Identification}

A total of 67 clinical isolates of $S$. aureus were collected from Department of Microbiology of Vijayanagara Institute of Medical Sciences, Bareilly, Utter Pradesh, India, Sanjay Gandhi Post Graduate Institute of Medical Sciences (SGPGI), Lucknow, India and Baba Farid University of Health Sciences, Faridkot, Punjab, India. These isolates were collected from blood, urine, pus swab and sputum of patients with their informed consent. All specimens were inoculated onto mannitol salt agar and incubated at 
$37^{\circ} \mathrm{C}$ and observed for 3 days. $S$. aureus isolates were confirmed by Gram staining, catalase test, oxidase test, coagulase test and growth characteristics on mannitolsalt agar (Akbar et al., 2013).

\section{DNA Isolation}

DNA from all clinical isolates was isolated according to the methods described earlier (Chaudhary and Payasi, 2013).

\section{Identification of MRSA}

MRSA isolates were identified by the presence of mecA gene as reported earlier (Chaudhary and Payasi, 2013).

\section{Identification of PVL in MRSA Strains}

All the isolates confirmed to be MRSA were analyzed for the presence of PVL gene using the following primers: Luk-PV-F-5-ATCATTAGGTAAAATGTCTGGACATGATCCA-3 and Luk-PV-R-5 GCATCAASTGTATTGGATAGCAAAAGC-3. These primers were obtained from Sigma Aldrich Chemicals Private Limited, Bangalore, India. For PCR amplification, about $200 \mathrm{pg}$ of DNA was added to $20 \mu \mathrm{L}$ of reaction system containing $0.5 \mathrm{mM}$ of dNTPs, 1.25 $\mu \mathrm{M}$ of each primer and $3.0 \mathrm{U}$ of Taq polymerase (Banglore Genei) in 1x PCR buffer. Amplification was performed in a Eppendorf thermocycler (Germany) with cycling parameters: Initial denauration at $94^{\circ} \mathrm{C}$ for $5 \mathrm{~min}$ followed by 30 cycles $\left(30 \mathrm{sec}\right.$ of denaturation at $94^{\circ} \mathrm{C}, 30$ $\mathrm{s}$ of annealing at $55^{\circ} \mathrm{C}, 1 \mathrm{~min}$ of extension at $72^{\circ} \mathrm{C}$ ) and final extension at $72^{\circ} \mathrm{C}$ for $1 \mathrm{~min}$. PCR products were analyzed by $1.0 \%$ agarose gel electrophoresis. The expected amplicon size was 433 base pairs.

\section{Minimun Inhibitory Concentration (MIC) Testing}

MICs of all drugs were determined by the agar dilution method following the Clinical and Laboratory Standards Institute (CLSI, 2013) guidelines. MIC was defined as the lowest concentration of drugs that inhibit the visible growth of a microorganism when incubated at $37^{\circ} \mathrm{C}$ for $18 \mathrm{~h}$. Two fold serial dilutions of drugs were used for the MIC study. Strains were classified as resistance or susceptible according to the criteria recommended by CLSI (2013).

\section{Isolation of PVL Toxin from S. aureus}

Ten selected PVL positive MRSA strains were used for the study. Twenty mililitre of each overnight grown MRSA strain was pelleted at $5000 \mathrm{rpm}$ for $5 \mathrm{~min}$, washed twice with phosphate buffer saline (PBS, $0.5 \mathrm{M}, \mathrm{pH} 7.4$ ) and was suspended in $10 \mathrm{~mL}$ of the PBS. Following addition of 500 $\mu \mathrm{L}$ of SDS $(10 \% \mathrm{w} / \mathrm{v})$ into each tube, suspension was incubated for $3 \mathrm{~h}$ at $37^{\circ} \mathrm{C}$, centrifuged at $12000 \mathrm{rpm}$ for 15 min and resulting supernatant was used as a crude PVL for further study. S. aureus ATCC 49775 served as the reference strain for PVL production. Isolated PVL from clinical isolates was pooled and used for study.

\section{PVL Quantification}

PVL quantification was performed by an antibodysandwich Enzyme-Linked Immunosorbent Assay (ELISA) with primary monoclonal antibody (Mouse anti-Luks-PV mAB), secondary antibody (anti Horseradish Peroxidase (HRP) conjugate) and detection antibody (polyclonal anti PVL LukS) following the manufacturer instructions. Briefly, $50 \mu \mathrm{L}$ of anti-LukSPV monoclonal antibody $\left(20 \mu \mathrm{g} \mathrm{mL}^{-1}\right.$ in phosphatebuffered saline (PBS, pH 7.4, $0.05 \mathrm{M}$ ) was added into each well of microtiter plate (Greiner Bio-One, USA) and incubated overnight at $4^{\circ} \mathrm{C}$ for binding. After incubation, plate was washed twice with PBS to remove unbound monoclonal antibody and nonspecific binding sites were blocked with a PBS-BSA solution (1\%) for $2 \mathrm{~h}$ at $37^{\circ} \mathrm{C}$ and again plate was washed twice with PBS and then $100 \mu \mathrm{L}$ of standard recombinant LukS-PV dilutions (from 0.005 to $1.0 \mu \mathrm{g} \mathrm{mL}^{-1}$ in PBSBSA $(1 \%)$ or samples (diluted in PBS-BSA (1\%) was added to duplicate wells and incubated for $2 \mathrm{~h}$ at $37^{\circ} \mathrm{C}$. After incubation plate was washed twice with PBS and $100 \mu \mathrm{L}$ of polyclonal anti PVL-LukS antibody $(20 \mu \mathrm{g}$ $\mathrm{mL}^{-1}$ in PBS) was added to each well, incubated for $2 \mathrm{~h}$ and washed twice with PBS. Subsequently, $100 \mu \mathrm{L}$ of secondary antibody HRP conjugated rabbit polyclonal anti-LukS-PV, diluted in the ratio of 1:1000 in blocking buffer, was added into each well and incubated for 30 min at $37^{\circ} \mathrm{C}$ and washed the plates with PBS for three times. Finally, $100 \mu \mathrm{L}$ of TMB solution was added into each well and incubated for another $20 \mathrm{~min}$. After 20 min incubation, the reaction was stopped by adding stop solution $(1 \mathrm{~N} \mathrm{HCl})$. The plate was read at $450 \mathrm{~nm}$ with ELISA reader (Bio-Rad). Values are shown as mean \pm SD of three experiments.

\section{Neutrophil Cell Isolation}

Human neutrophils were isolated according to the method described elsewhere (Kobayashi et al., 2003).

\section{Cell Culture}

The neutrophils were cultured in RPMI 1640 culture medium (Hi-Media, Mumbai, India) supplemented with $10 \% \mathrm{FBS}$ and $1 \%$ antibiotic/antimyotic solution at $37^{\circ} \mathrm{C}$ in an atmosphere of $5 \% \mathrm{CO}_{2}$ in a humidified incubator.

\section{Effect of Different Concentrations of PVL on Neutrophils}

To study the effect of various concentrations of PVL on neutrophils, $100 \mu \mathrm{L}$ of neutrophils $\left(1 \times 10^{7}\right.$ cells $\mathrm{mL}^{-1}$ ) were seeded into 96-well plate and incubated for $2 \mathrm{~h}$ at $37^{\circ} \mathrm{C}$ with $5 \% \mathrm{CO}_{2}$ in the absence and presence of different concentrations of PVL $(0.025,0.05$, 0.1 and $0.15 \mu \mathrm{g} \mathrm{mL}$ ). After incubation, plate was centrifuged at $1000 \mathrm{rpm}$ for $7 \mathrm{~min}$ at $4^{\circ} \mathrm{C}$. Aliquots $(100 \mu \mathrm{L})$ from each well were transferred to a another 96-well plate and percent LDH release was determined as described below. 


\section{Lactate Dehydrogenase Activity (LDH) Assay}

Lysis of neutrophils by PVL was assessed by the release of LDH. LDH was assayed using a kit (Sigma Aldrich, USA) according to the manufacturer's instructions. The absorbance was measured at $450 \mathrm{~nm}$. Values are shown as mean \pm SD of three experiments. Percentage of LDH release was calculated using followings formula:

$$
L D H \text { release }(\%) \frac{\text { Control }_{O D}-\text { Test }_{O D}}{\text { Control }_{O D}} \times 100
$$

Effect of Adjuvants (L-lysine, L-arginine, EDTA) on PVL Induced Lysis of Neutrophils

To study the ability of amino acids, L-lysine, Larginine and EDTA to inhibit PVL induced lysis of neutrophils, isolated neutrophils were seeded into 96 well plate and divided into 17 groups designated as group A, B, C, D, E, F, G, H, I, J, K, L, M, N, O, P and Q. Cells in group A were treated with $\mathrm{PBS}$ served as a negative control. Cells in group B to Q were stimulated with PVL $\left(0.1 \mu \mathrm{g} \mathrm{mL}^{-1}\right)$ and cells in group $\mathrm{B}$ served as positive control. Cells in $\mathrm{C}$ to $\mathrm{Q}$ groups were simultaneously treated with $5,10,50,100$ and $150 \mathrm{mM}$ concentrations of each of EDTA, L-lysine and L-arginine. Only cell culture media in another group $\mathrm{R}$ was served as a blank. The plate was then incubated for $2 \mathrm{~h}$ in $\mathrm{CO}_{2}$ incubator $\left(37^{\circ} \mathrm{C}, 5 \%\right.$ $\mathrm{CO}_{2}$ ). Following $2 \mathrm{~h}$ of incubation, plate was centrifuged at $1000 \mathrm{rpm}$ for $7 \mathrm{~min}$ at $4^{\circ} \mathrm{C}$. Aliquots $(100 \mu \mathrm{L})$ from each well were transferred to another 96-well plate and LDH was measured and calculated as described above.

Further, different combinations of adjuvants, L-lysine + EDTA, L-Lysine + L-arginine and L-arginine + EDTA were made and evaluated on PVL induced neutrophils lysis. For this, neutrophils were divided into 5 groups named as group A, B, C, D and E. Cells in group a treated with PBS and served as negative control. Cells in group B to $\mathrm{E}$ were stimulated with PVL $\left(0.1 \mu \mathrm{g} \mathrm{mL}^{-1}\right)$ and cells in froup B served as positive control. Cell in group $\mathrm{C}$ to $\mathrm{E}$ simultaneously treated with $10 \mathrm{mM}$ L-lysine $+10 \mathrm{mM}$ EDTA, $10 \mathrm{mM}$ L-Lysine $+100 \mathrm{mM}$ L-arginine and 100 $\mathrm{mM}$ L-arginine $+10 \mathrm{M}$ EDTA, incubated for $2 \mathrm{~h}$. Only cell culture media in another group F served as blank. After incubation and centrifugation, $100 \mu \mathrm{L}$ of supernatant was used to measure LDH as described above.

\section{Effect of Drugs on PVL Induced Neutrophil Lysis}

To evaluate the effect of drugs, Vancoplus, vancomycin, linezolid, daptomycin and teicoplanin, on PVL induced neutrophils lysis, neutrophils were seeded into 96 well plate and grouped as follows; group A, B, C, D, E, F and G. Cells in group A were treated with PBS which served as a negative control. Cells in group $B$ to $G$ were stimulated with PVL $\left(0.1 \mu \mathrm{g} \mathrm{mL}^{-1}\right)$ and cells in group B served as positive control. Cells in $\mathrm{C}, \mathrm{D}, \mathrm{E}, \mathrm{F}$ and $\mathrm{G}$ groups were simultaneously treated with half of MIC of each of drugs Vancoplus, vancomycin, linezolid, daptomycin and teicoplanin. Only cell culture media in another group $\mathrm{H}$ served as a blank. Here, Vancoplus was reconstituted with solvent (provided with pack by manufacturer as per manufacturer's instructions) whereas remaining drugs were reconstituted in water. The procedure for $\mathrm{LDH}$ measurement was the same as described above.

\section{Statistical analysis}

All data were represented the mean \pm SD of three independent experiments. The data were further analyzed using Graph pad prism 5.01 in different groups compared with control by one way ANOVA and Tukey's test. Values of $p>0.05$ were considered not to be significant.

\section{Results}

\section{Identification of clinical isolates}

All the 67 isolates were confirmed to be $S$. aureus according to their biochemical test results. Out of 67 clinical isolates, $71.6 \%(48 / 67)$ isolates were found to be MRSA as confirmed by the presence of mecA gene through PCR amplification. Amplification of $m e c A$ in some isolates is shown in Fig. 1.

\section{Prevalence of PVL in Clinical Specimens}

All 48 MRSA were analysed for the presence of PVL gene. Of these, $75 \%(36 / 48)$ isolates were noted to be PVL positive as evident by PCR producting 433 base pair amplicon (Fig. 2). The proportions of the PVL in the strains varied depending upon the clinical specimens. The frequency of PVL in the different specimens is shown in Table 1. Pus swab $(86.3 \% ; 19 / 22)$ had more proportion of PVL than Urine $(75 \% ; 6 / 8)$; sputum $(70 \%$; $7 / 10)$ and blood $(50 \% ; 4 / 4)$.

MIC

MIC testing was carried out in only PVL positive MRSA strains and results are depicted in Table 2. Of the tested drugs, vancoplus was found to be the most efficacious drugs with MIC values 0.25 to $4 \mu \mathrm{g} \mathrm{mL}^{-1}$.

Table 1. Frequency of PVL gene in MRSA isolates obtained from different specimens

\begin{tabular}{llll}
\hline & PVL gene frequency & \\
\cline { 2 - 4 } Specimens & Present & Absent & Total \\
\hline Urine & 6 & 2 & 8 \\
Pus swab & 19 & 3 & 22 \\
Blood & 4 & 4 & 8 \\
Sputum & 7 & 3 & 10 \\
Total & 36 & 12 & 48 \\
\hline
\end{tabular}

Table 2. MIC of drugs against PVL positive isolates

\begin{tabular}{lll}
\hline Drugs & MIC $(\mu \mathrm{g} / \mathrm{mL})$ & $1 / 2 \mathrm{MIC}(\mu \mathrm{g} / \mathrm{mL})$ \\
\hline Vancoplus & 0.25 to 4 & 0.125 to 2 \\
Linezolid & 1 to 32 & 0.5 to 16 \\
Teicoplanin & 2 to 32 & 1 to 16 \\
Vancomycin & 1 to 64 & 0.5 to 32 \\
Daptomycin & 0.5 to 32 & 0.25 to 32 \\
\hline
\end{tabular}




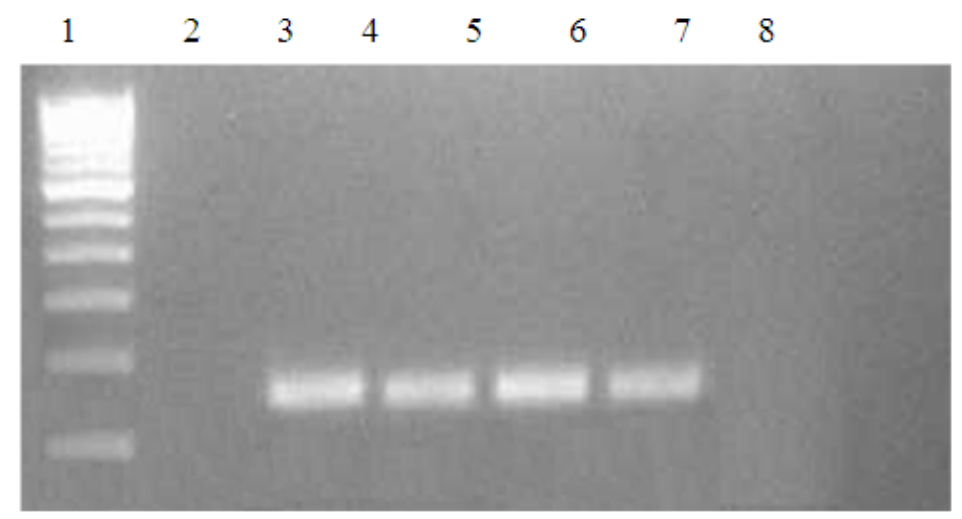

Fig. 1. Amplification of mec A gene in clinical isolates of $S$. aureus by polymerase chain reactionas

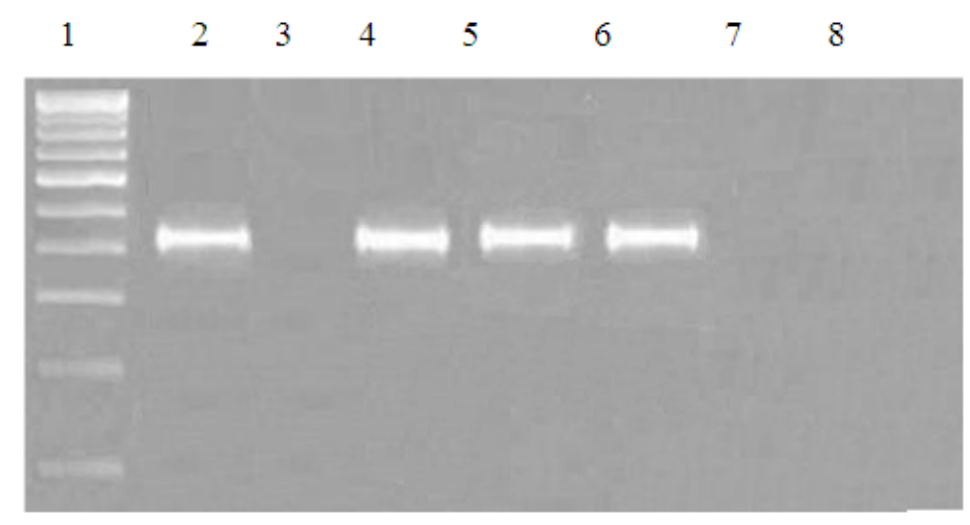

Fig. 2. Amplification of PVL gene in clinical islates of MRSA

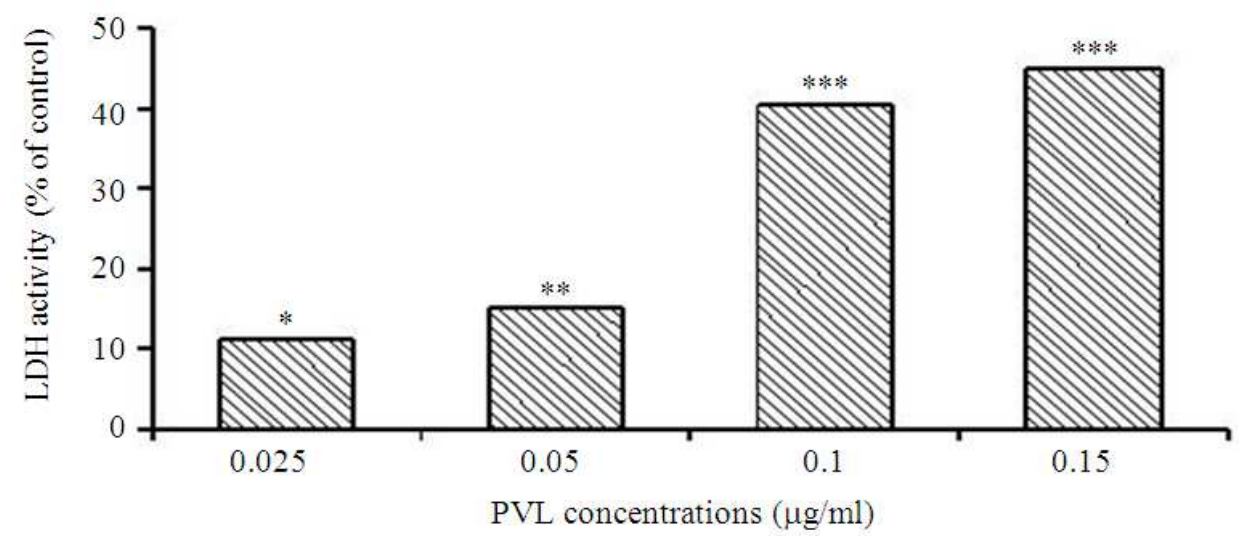

Fig. 3. Percentage increase in LDH activity

The MICs of linezolid and teicoplanin were ranged 1-32 and 2-32 $\mu \mathrm{g} \mathrm{mL} \mathrm{m}^{-1}$, respectively. The MICs of vancomycin and daptomycin varied 1-64 and 0.5 to $32 \mu \mathrm{g} \mathrm{mL} \mathrm{m}^{-1}$. For further study, half of MIC of drugs were used. All the drugs displayed variability in MIC values indicating strains have different susceptibility behaviour towards drugs due to presence of various types of resistant determinants. The types of resitant determinants were not studied here as it was not part of this study.

\section{Effect of Different Concentration of PVL on Neutrophils}

To determine whether PVL induces neutrophil lysis, we measured LDH release into the media following $2 \mathrm{~h}$ PVL exposure. Treatment with different concentrations of PVL $\left(0.025\right.$ to $\left.0.15 \mu \mathrm{g} \mathrm{mL}^{-1}\right)$ resulted in a concentration dependent increase in $\mathrm{LDH}$ activity which were statistically significant $(p<0.05$ to $p<0.001)$ in 
comparision to control (Table 3). Treatment of neutrophil cells with $0.025,0.05,0.1$ and $0.15 \mu \mathrm{g} \mathrm{mL}^{-1}$ resulted in $11.1,15.2,40.6$ and $45.1 \%$ increase in $\mathrm{LDH}$ activity, respectively (Fig. 3).

Effect of Adjuvants (L-lysine, L-arginine, EDTA) on PVL Induced Lysis of Neutrophils by LDH Assay

According to the results presented in Table 4, all the adjuvents (L-lysine, L-arginine, EDTA) inhibited the PVL induced neutrophil cell lysis in a concentration dependent manner. The inhibition of LDH increased with increasing the concentrations of these adjuvants. L-lysine caused $33.8 \pm 2.8$ and $78.7 \pm 7.1 \% \mathrm{LDH}$ inhibition at 5 and $10 \mathrm{mM}$ in comparision to control, respectively and further increasing its concentrations had no significant increase in $\mathrm{LDH}$ inhibition. On the other hand, $18.8 \pm 2.3,32.3 \pm 3.6$, $67.5 \pm 7.1,79.5 \pm 8.2$ and $83.5 \pm 8.1 \%$ inhibition of LDH activities were observed with 5, 10, 50, 100 and $150 \mathrm{mM}$ of L-arginine in comparison to control. These results suggest that the $10 \mathrm{mM}$ of L-lysine produced significant (78.7 $\pm 7.1 \%)$ LDH inhibition at 15 times lower concentration which is comparable to $100 \mathrm{mM}$ of Larginine (79.5 $\pm 8.2 \% \mathrm{LDH}$ inhibition).

EDTA was the least effective in the inhibition of PVL induced neutrophil cell lysis. It displayed only $12.5 \pm 1.7$, $20.2 \pm 2.4,24.2 \pm 2.6,27.4 \pm 3.2$ and $29.7 \pm 3.3 \% \mathrm{LDH}$ inhibition at 5, 10,50,100 and $150 \mathrm{mM}$ when compared with control. Further, our results showed that EDTA up to $10 \mathrm{mM}$ produced sharp increase in $\mathrm{LDH}$ inhibition and thereafter remained constant. Overall, results suggest that $10 \mathrm{mM}$ L-lysine and $150 \mathrm{mM}$ L-arginine more efficiently inhibit the PVL induced neutrophil cell lysis.

When the best performing combinations of Llysine + EDTA, L-Lysine + L-arginine and L-arginine + EDTA were tested on PVL induced neutrophil cell lysis, an additive effect was observed and $100 \mathrm{mM} \mathrm{L}$ arginine $+10 \mathrm{mM}$ EDTA could inhibit up to $93.4 \pm 6.3 \%$ LDH activity (Table 5).

\section{Effect of Drugs on PVL Induced Neutrophil Lysis}

When various drugs were tested to evaluate their ability to inhibit PVL induced neutrophils lysis, we noted that Vancoplus efficiently inhibit PVL induced neutrophil lysis as it produced $93.1 \pm 6.4 \%$ inhibition of LDH activity. While vancomycin, linezolid, daptomycin and teicoplanin showed only $12.7 \pm 2.4,26.7 \pm 3.4,16.5 \pm 2.3$ and $30.5 \pm 3.1 \%$ inhibition of LDH activity (Table 6).

Table 3. Effect of different concentrations of PVL on neutrophils

\begin{tabular}{lll}
\hline $\begin{array}{l}\text { PVL concentration } \\
(\mu \mathrm{g} / \mathrm{ml})\end{array}$ & $\begin{array}{l}\text { LDH activity } \\
(\mathrm{nmol} / \mathrm{min} / \mathrm{ml})\end{array}$ & P-value \\
\hline Control & $0.3 \pm 0.03$ & \\
0.025 & $3.5 \pm 0.3$ & $\mathrm{p}<0.05(*)$ \\
0.05 & $4.7 \pm 0.4$ & $\mathrm{p}<0.01(* *)$ \\
0.1 & $12.6 \pm 1.4$ & $\mathrm{p}<0.001(* * *)$ \\
0.15 & $14.0 \pm 1.4$ & $\mathrm{p}<0.001(* * *)$ \\
\hline
\end{tabular}

Table 4. Effect of adjuvants on PVL induced lysis of neutrophils

\begin{tabular}{lcc}
\hline $\begin{array}{l}\text { Name of } \\
\text { adjuvants }\end{array}$ & $\begin{array}{l}\text { Concentration } \\
(\mathrm{mM})\end{array}$ & $\begin{array}{l}\text { LDH } \\
\text { inhibition (\%) }\end{array}$ \\
\hline L-lysine & 5 & $33.8 \pm 2.8$ \\
& 10 & $78.7 \pm 7.1$ \\
& 50 & $81.3 \pm 7.2$ \\
& 100 & $83.1 \pm 8.4$ \\
L-arginine & 150 & $84.5 \pm 8.1$ \\
& 5 & $18.8 \pm 2.3$ \\
& 10 & $32.3 \pm 3.6$ \\
& 50 & $67.5 \pm 7.1$ \\
EDTA & 100 & $79.5 \pm 8.2$ \\
& 150 & $83.5 \pm 8.1$ \\
& 5 & $12.5 \pm 1.7$ \\
& 10 & $20.2 \pm 2.4$ \\
& 50 & $24.2 \pm 2.6$ \\
& 100 & $27.4 \pm 3.2$ \\
& 150 & $29.7 \pm 3.3$ \\
\hline
\end{tabular}

Table 5. Effect of combinations of adjuvents on PVL induced lysis of neutrophils

\begin{tabular}{ll}
\hline Combinations of adjuvants & LDH inhibition (\%) \\
\hline $10 \mathrm{mM}$ L-lysine $+10 \mathrm{mM}$ EDTA & $92.6 \pm 8.8$ \\
$10 \mathrm{mM}$ L-lysine $+100 \mathrm{mM}$ L-arginine & $90.6 \pm 8.4$ \\
$100 \mathrm{mM}$ L-arginine $+10 \mathrm{~m}$ M EDTA & $93.4 \pm 6.3$ \\
\hline
\end{tabular}

Table 6. Effect of drugs on PVL induced lysis of neutrophils

\begin{tabular}{ll}
\hline Drugs & LDH inhibition (\%) \\
\hline Vancoplus & $93.1 \pm 6.4$ \\
Vancomycin & $12.7 \pm 2.4$ \\
Linezolid & $26.7 \pm 3.4$ \\
Daptomycin & $16.5 \pm 2.3$ \\
Teicoplanin & $30.5 \pm 3.1$ \\
\hline
\end{tabular}

The gel lanes are: $1=$ molecular weight ladder (100 bp), $2=S$. aureus ATCC 25923 (negative control), $3=S$. aureus ATCC 43300 (positive control), 4-6 = S. aureus (mecA positive isolates), 7-8 $=S$. aureus (mecA negative isolates).

The gel lanes are: $1=$ molecular weight ladder $(100 \mathrm{bp})$, $2=S$. aureus ATCC 49775 (positive control), 3 S. aureus MTCC 737 (negative control) = 4-6 = S. aureus (PVL positive isolates), 7-8 $=S$. aureus (PVL negative isolates).

\section{Discussion}

Over the past several decades, the incidence of resistant gram-positive organisms has risen throughout the world. Among these, MRSA are predominant pathogens associated with serious infections. Both human and rabbit neutrophils are highly sensitive to the pore-forming properties of PVL and rapidly undergo cell death (Ma et al., 2012). Plenty of studies have reported that PVL is one of the major virulence factors contributing to the morbidity and mortality attributed to $S$. aureus (Omuse et al., 2013; Gillet et al., 2008; Gillet et al., 2002). Current 
investigation demonstrated the prevalence of MRSA to be $71.6 \%$. Previous studies demonstrated the incidence of MRSA in India to be 30-70\% (Singh et al., 2012; Muralidharan, 2009; Chaudhary and Payasi, 2013). Further analysis of these MRSA for prevalence of PVL, overall prevalence of the PVL gene in MRSA isolates was around $75 \%$. The prevalence of PVL in MRSA obtained in our study is little higher than that of previous studies performed in Africa and Kenya where PVL prevalence was reported to be 57 and $58 \%$, respectively (Breurec et al., 2010; Omuse et al., 2013). However, our result is close to the 70 and $72 \%$ obtained in Benin and Algeria, respectively (Sina et al., 2013; Campbell et al., 2008). In the current study PVL was the most prevalent in pus swab followed by urine, sputum and blood. Our observations clearly indicates that prevalence of PVL varies with geographical locations and clinical specimens. Previous study also noted that PVL prevalence vary with clinical specimens (Goering et al., 2008). It has been reported that compared with PVLnegative $S$. aureus isolates, PVL-positive isolates are more pathogenic because the lytic activity of PVL directly affects monocytes, macrophages, polynuclear neutrophils and metamyelocytes, although erythrocytes are not lysed by PVL (Prévost et al., 2001; Barr et al., 2006; Kazakova et al., 2005). Moreover, PVL toxin is reported to have a cytolytic effect and as such polynuclear neutrophils were identified as important indicators of staphylococcal virulence (Cribier et al., 1992).

In the last decade dramatic changes have occurred in the epidemiology of MRSA infections. The antibiotic sensitivity pattern of MRSA isolated from clinical specimens were found to be highly variable. Our susceptibility data demonstrated that vancomycin appeared to be resistant to $77.7 \%(28 / 36)$ strains of PVL positive followed by daptomycin 55.5\% (20/36), teicoplanin $33.3 \%(12 / 36)$, linezolid $22.2 \%(8 / 36)$ and Vancoplus $5.5 \%(2 / 36)$. No previous study of this nature has been done.

In our study, $22.2 \%$ isolates were resistant to linezolid which is very close to the study performed by Thool et al. (2012) in which $23.5 \%$ resistant to linezolid was observed. Resistance to linezolid may be explained by the fact that mutations in the $23 \mathrm{~s}$ rRNA of the $50 \mathrm{~s}$ ribosomal subunit resulting in alteration of linezolid-binding sites of the bacteria (Long et al., 2010; Nannini et al., 2010). Our data showed that there is a drastic rise of resistance of glycopeptide (vancomycin, teicoplanin) and lipopeptide (daptomycin). The emergence of the glycopeptide resistance is of serious concern for the treatment of infections caused by Gram positive organisms particluarly MRSA. A number of other studies have also pointed out the reduced susceptibility of glycopeptide and lipopeptide to MRSA (Estes and Derendorf, 2010; Judge et al., 2012). The reduced susceptibility of glycopeptide is explained by the fact that trapping of glycopeptide in the peptidoglycan of the bacterial cell causing decreased reaching of glycopeptide to the cytoplasmic membrane where the targets of glycopeptides are located (Westerlind, 2012). Resistance of daptomycin has also been associated with alteration in the structure and function of the cell envelope and surface charge.

Our results showed that $94.5 \%$ of PVL positive MRSA were sensitive to Vancoplus, the novel antibiotic adjuvant entity. The enhanced susceptibility of Vancoplus is because of synergistic activity. When ceftriaxone and vancomycin are used in combination there are less chances of trapping of these molecules in the peptidoglycan as a result enhanced susceptibility. Additionally, Vancoplus contains animo acids (VRP1020) for chemical compatibility and is reconstituted with solvent, it neutralizes more than $95 \%$ of PVL toxins. By neutralizing PVL toxins it can avoid the side effects caused by PVL when treated during MRSA infections, especially in immunocompromised patients.

\section{Conclusion}

This study provides new insight into the prevalence of PVL toxins among MRSA. Results of this study showed that of the tested drugs, Vancoplus is the most active against MRSA positive with PVL toxins and is highly effective in PVL neutralization thereby causing lesser neutrophil lysis in comparison to comparator drugs and can be a safer and more effective therapy for MRSA management.

\section{Acknowledgment}

The researchers are thankful to Emerging Antimicrobial Resistance Society, Chandigadh, India for providing assistance to carry out this study. Also thankful to Vijayanagara Institute of Medical Sciences, Bareilly, Utter Pradesh, India, Sanjay Gandhi Post Graduate Institute of Medical Sciences (SGPGI), Lucknow, India and Baba Farid University of Health Sciences, Faridkot, Punjab, India. for providing clinical strains.

\section{Funding Information}

Authors are thankful to sponsor, Venus Medicine Research Centre, Werne, Germany, for providing financial assistance (Grant no. VPG-105-2014) to carry out this study.

\section{Author's Contributions}

MC and AP designed the experimental work and analyzed the results. SKP carried out all experiments.

\section{Ethics}

We declare that we have no ethical issue. 


\section{References}

Akbar, M.T., A.M. Habib, D.U. Chowdhury, M.I. Bhuiyan and K.M. Mostafa et al., 2013. An insight into the lignin peroxidase of Macrophomina phaseolina. Bioinformation, 9: 730-735.

DOI: $10.6026 / 97320630009730$

Baba-Moussa, L., H. Ahissou, P. Azokpota, B. Assogba and M. Atindéhou et al., 2010. Toxins and adhesion factors associated with Staphylococcus aureus strains isolated from diarrheal patients in Benin. Afr. J. Biotechnol., 9: 604-611.

Breurec, S., C. Fall, R. Pouillot, P. Boisier and S. Brisse et al., 2010. Epidemiology of methicillinsusceptible Staphylococcus aureus lineages in five major African towns: High prevalence of panton-valentine leukocidin genes. Clin. Microbiol. Infect., 17: 633-639.

DOI: 10.1111/j.1469-0691.2010.03320.x

Barr, B., M. Felkner and P. Diamond, 2006. High school athletic departments as sentinel surveillance sites for community-associated methicillin-resistant staphylococcal infections. Texas Med., 102: 156. PMID: 17128759

Chaudhary, M. and A. Payasi, 2013. Prevalence of heterogeneous glycopeptide intermediate resistance in methicillin-resistant Staphylococcus aureus. Am. J. Infect. Dis., 9: 63-70.

DOI: 10.3844 ajidsp.2013.63.70

Campbell, S.J., H.S. Deshmukl, C.L. Nelson and I. Bae, 2008. Genotypic characteristics of Staphylococcus aureus isolates from a multinational trial of complicated skin and skin structure infections. J. Clin. Microbiol., 46: 678-684.

DOI: $10.1128 /$ JCM.01822-07

Clinic, M., T.H.E. Birbeck and J.P. Arbuthnott, 1992. Characterization of staphylococcal $\lambda$-lysin. J. Gen. Microbiol., 138: 923-930.

DOI: $10.1099 / 00221287-138-5-923$

CLSI, 2013. Methods for dilution antimicrobial susceptibility tests for bacteria that grow aerobically: Approved standard. Clinical and Laboratory Standard Institute, USA.

Cribier, B., G. Prevost, P. Couppie, V. Finck-Barbancon and E. Grosshans et al., 1992. Staphylococcus aureus leukocidin: A new virulence factor in cutaneous infections. An epidemiological and experimental study. Dermatology, 185: 175-180. DOI: 10.1159/000247443

Corey, G.R., 2009. Staphylococcus aureus bloodstream infections: definitions and treatment. Clin. Infect. Dis., 48: 254-259. DOI: 10.1086/598186

Dinges, M.M., P.M. Orwin and P.M. Schlievert, 2000. Exotoxins of Staphylococcus aureus. Clin. Microbiol. Rev., 13: 16-34.

DOI: $10.1128 / \mathrm{CMR} .13 .1 .16-34.2000$
Durupt, F., L. Mayor, M. Bes, M.E. Reverdy and F. Vandenesch et al., 2007. Prevalence of Staphylococcus aureus toxins and nasal carriage in furuncles and impetigo. Br. J. Dermatol., 157: 11611167. DOI: $10.1111 / \mathrm{j} .1365-2133.2007 .08197 . \mathrm{x}$

Estes, K.S. and H. Derendorf, 2010. Comparison of the pharmacokinetic properties of vancomycin, linezolid, tigecyclin and daptomycin. Eup. J. Med. Res., 30: 533-543. DOI: 10.1186/2047-783X-15-12-533

Goering, R.V., R.M. Shawar, N.E. Scangarella, F.P. OHara and H. Amrine-Madsen et al., 2008. Molecular epidemiology of methicillin-resistant and methicillinsusceptible Staphylococcus aureus isolates from global clinical trials. J. Clin. Microbiol., 9: 2842-2847. DOI: $10.1128 / \mathrm{JCM} .00521-08$

Gillet, Y., B. Issartel, P. Vanhems, J.C. Fournet and G. Lina et al., 2002. Association between Staphylococcus aureus strains carrying gene for Panton-Valentine leukocidin and highly lethal necrotising pneumonia in young immunocompetent patients. Lancet, 359: 753-759. DOI: 10.1016/S0140-6736(02)07877-7

Gillet, Y, J. Etienne, G. Lina and F. Vandenesch, 2008. Association of necrotizing pneumonia with panton-valentine leukocidin-producing Staphylococcus aureus, regardless of methicillin resistance. Clin. Infect. Dis., 47: 985-986. DOI: $10.1086 / 591803$

Gillet, Y., B. Dohin, O. Dumitrescu, G. Lina and F. Vandenesch et al., 2007. Osteoarticular infections with staphylococcus aureus secreting Panton-valentine leucocidin. Arch. Pediatr., 14: 102-107. DOI: 10.1016/S0929-693X(07)80043-1

Howden, B.P., P.B. Ward and P.G. Charles, T.M. Korman and A. Fuller et al., 2004. Treatment outcomes for serious infections caused by methicillin-resistant Staphylococcus aureus with reduced vancomycin susceptibility. Clin. Infect. Dis., 38: 521-8. PMID: 14765345

Holmes, A., M. Ganner, S. McGuane, T.L. Pitt and B.D. Cookson et al., 2005. Staphylococcus aureus isolates carrying Panton-valentine leucocidin genes in England and Wales: Frequency, characterization and association with clinical disease. J. Clin. Microbiol., 43: 2384-2390.

DOI: 10.1128/JCM.43.5.2384-2390.2005

Jang, H.C., S.J. Kang, S.M. Choi, K.H. Park, J.H. Shin, H.E. Choy, S.I. Jung and H.B. Kim, 2012. Difference in $a g r$ dysfunction and reduced vancomycin susceptibility between MRSA bacteremia involving SCCmec types IV/IVa and IIII. PLoS One, 7: 49136-49136.

DOI: $10.1371 /$ journal.pone.0049136

Judge, T., J.M. Pogue, D. Marchaim, K. Ho and S. Kamatam et al., 2012. Epidemiology of vancomycinresistant enterococci with reduced susceptibility to daptomycin. Infect. Control Hosp. Epidemiol., 33: 1250-1254. DOI: $10.1086 / 668438$ 
Karunakaran, R., S.T. Tay, F.F. Rahim, B.B. Lim and I.C. Sam et al., 2012. Ceftriaxone resistance and genes encoding extended-spectrum $\beta$-lactamase among non-typhoidal Salmonella species from a tertiary care hospital in Kuala Lumpur, Malaysia. Jpn. J. Infect. Dis., 65: 433-435.

DOI: 10.7883 /yoken.65.433

Kazakova, S.V., J.C. Hageman, M. Matava, A. Srinivasan and L. Phelan et al., 2005. A clone of methicillin-resistant Staphylococcus aureus among professional football players. N Eng. J. Med., 352: 468-75. DOI: 10.1056/NEJMoa042859

Kluytmans, A., A. van Belkum and H. Verbrugh, 1997. Nasal carriage of Staphylococcus aureus: Epidemiology, underlying mechanisms and associated risks. Clin. Microb. Rev., 10: 505-520. PMID: 9227864

Kobayashi, S.D., J.M. Voyich, G.A. Somerville, K.R. Braughton and H.L. Malech et al., 2003. An apoptosis-differentiation program in human polymorphonuclear leukocytes facilitates resolution of inflammation. J. Leuk. Biol., 73: 315-322. DOI: 10.1189/jlb.1002481

Korkmaz, B., T. Moreau and F. Gauthier, 2008. Neutrophil elastase, proteinase 3 and cathepsin G: Physicochemical properties, activity and physiopathological functions. Biochimie, 90: 227-42. DOI: $10.1016 /$ j.biochi.2007.10.009

Labandeira-Rey, M., F. Couzon, S. Boisset, E.L. Brown and M. Bes et al., 2007. Staphylococcus aureus Panton-valentine leukocidin causes necrotizing pneumonia. Science, 315: 1130-1133. DOI: $10.1126 /$ science. 1137165

Lina, G., Y. Piemont, F. Godail-Gamont, M. Bes and M.O. Peter et al., 1999. Involvement of PantonValentine leukocidin-producing Staphylococcus aureus in primary skin infections and pneumonia. Clin. Infect. Dis., 29: 1128-1132. DOI: 10.1086/313461

Long, K.S., C. Munck, T.M.B. Anderson, M.A. Schaub and S.N. Hobbie et al., 2010. Mutations in $23 \mathrm{~S}$ rRNA at the peptidyl transferase center and their relationship to linezolid binding and crossresistance. Antimicrob. Agents Chemother., 54: 4705-4713. DOI: 10.1128/AAC.00644-10

Ma, X., W. Chang, C. Zhang, X. Zhou and F. Yu, 2012. Staphylococcal panton-valentine leukocidin induces pro-inflammatory cytokine production and nuclear factor-kappa B activation in neutrophils. PLoS ONE, 7: 34970-34970. DOI: 10.1371/journal.pone.0034970

Muralidharan, S., 2009. Special article on methicillin resistant Staphylococcus aureus. J. Acad. Clin. Microbiol., 11: 15-6.
Nannini, E., B.E. Murray and C.A. Arias, 2010. Resistance or decreased susceptibility to glycopeptides, daptomycin and linezolid in methicillin-resistant Staphylococcus aureus. Curr. Opin. Pharmacol., 10: 516-521.

DOI: $10.1016 /$ j.coph.2010.06.006

Niemann, S., C. Ehrhardt, E. Medina and K. Warnking, 2012. Combined action of influenza virus and Staphylococcus aureus Panton-valentine leukocidin provokes severe lung epithelium damage.. Inst. Med. Microbiol., 206: 1138-48. PMID: 22837490

Nizet, V., 2007. Understanding how leading bacterial pathogens subvert innate immunity to reveal novel therapeutic targets. J. Allergy Clin. Immunol., 120: 13-22.

DOI: 10.1016/j.jaci.2007.06.005

Nubel, U., P. Roumagnac, M. Feldkamp, J.H. Song and K.S. Ko et al., 2008. Frequent emergence and limited geographic dispersal of methicillin-resistant Staphylococcus aureus. Proc. Nat. Acad. Sci., 105: 14130-14135. DOI: 10.1073/pnas.0804178105

Omuse, G., P. Shivachi, S. Kariuki and G. Revathi, 2013. Prevalence of panton valentine leukocidin in carriage and infective strains of Staphylococcus aureus at a referral hospital in Kenya. Open J. Med. Microbiol., 3: 5-11. DOI: 10.4236/ojmm.2013.31002

Perichon, B. and P. Courvalin, 2009. VanA-type vancomycin-resistant Staphylococcus aureus. Antimicrob. Agents Chemother., 11: 4580-4587. DOI: 10.1128/AAC.00346-09

Prévost, G., L. Mourey, D.A. Colin and G.Menestrina, 2001. Staphylococcal pore-forming toxins. Curr. Top. Microbiol. Immunol., 257: 53-83. DOI: 10.1007/978-3-642-56508-3_4

Prevost, G., P. Couppie, V. Finck-Barbancon, E. Grosshans and Y. Piemont, 1993. Staphyloccocus aureus P83 suggests that stphylococcal leuocidins and gammahemolysin are members of a single, two-cpmponent family of toxin. Infect. Immun., 42: 273-45.

Reynolds, R., R. Hope, M. Warner, A.P. MacGowan and D.M. Livermore et al., 2012. Lack of upward creep of glycopeptide MICs for Methicillin-Resistant Staphylococcus aureus (MRSA) isolated in the UK and Ireland 2001-07. J. Antimicrob. Chemother., 67: 2912-8. DOI: 10.1093/jac/dks324

Singh, N.K.R., K. Kalia and J.S. Patel, 2012. A survey on prevalence rate and Antibiotic Susceptibility Test (AST) pattern of Methicillin-Resistant Staphylococcus aureus (MRSA) isolate from various types of clinical specimen and healthy hospital staff as carriers. Anand district. J. Pharm. Biomed. Sci., 16: 1-5. 
Sina, H., T.A. Ahoyo, W. Moussaoui, D. Keller and H.S. Bankolé et al., 2013. Variability of antibiotic susceptibility and toxin production of Staphylococcus aureus strains isolated from skin, soft tissue and bone related infections. BMC Microbiol., 13: 188-188. DOI: $10.1186 / 1471-2180-13-188$

Thati, V., C.T. Shivannavar and S.M. Gaddad, 2011. Vancomycin resistance among methicillin resistant Staphylococcus aureus isolates from intensive care units of tertiary care hospitals in Hyderabad. Ind. J. Med. Res., 134: 704-708. DOI: $10.4103 / 0971-5916.91001$

Thool, V.U., G.L. Bhoosreddy and B.J. Wadher, 2012. Detection of resistance to linezolid in Staphylococcus aureus infecting orthopedic patients. Ind. J. Pathol. Microbiol., 55: 361-364. PMID: 23032832
Veer, P., C. Chande, S. Chavan, V. Wabale and K. Chopdekar et al., 2010. Increasing levels of minimum inhibitory concentration vancomycin in methicillin resistant Staphylococcus aureus alarming bell for vancomycin abusers? Ind. J. Med. Microbiol., 28: 413-4.

DOI: $10.4103 / 0255-0857.71810$

Westerlind, U., 2012. Synthetic glycopeptides and glycoproteins with applications in biological research. Beilstein J. Org. Chem., 8:804-18.

DOI: $10.3762 /$ bjoc. 8.90 